\title{
Tongue protrusion force and fatiguability in male and female subjects
}

\author{
I.L. Mortimore, P. Fiddes, S. Stephens, N.J. Douglas
}

\begin{abstract}
Tongue protrusion force and fatiguability in male and female subjects. I.L. Mortimore, P. Fiddes, S. Stephens, N.J. Douglas. (C)ERS Journals Ltd 1999.

ABSTRACT: Limb and respiratory muscle (diaphragm) strength and fatiguability have been extensively studied in man and are known to vary with age and sex. However, in contrast to limb muscles and the diaphragm, force and fatiguability characteristics have not been studied in upper airway muscles.

This study examines the hypotheses that tongue protrusion strength or fatiguability, determined by the properties of the intrinsic muscles and genioglossus, may change with age and may be reduced in males compared to females. A force transducer was used to compare maximal tongue protrusion force $\left(F_{\max }\right)$ and fatiguability in 81 males and 86 females matched for age (mean \pm sD, $43 \pm 19$ yrs, $42 \pm 19$ yrs, respectively). Fatiguability indices were based on the time that subjects could maintain $50 \%$ of $F_{\text {max. }}$

$F_{\max }$ declined with age in both males $(\mathrm{r}=-\mathbf{0 . 5 7}, \mathrm{p}<0.001)$ and females $(\mathrm{r}=\mathbf{- 0 . 5 6}$, $p<0.001$ ). $F$ max in males was greater than in females (males $26 \pm 8 \mathrm{~N}$; females $20 \pm 7 \mathrm{~N}$; p $<0.001)$. However, after correction of $F$ max for sex differences in total body muscle (fat-free mass) there was no significant difference between males and females $(p=0.3)$. There was also no difference in fatiguability between males and females $(p=0.5)$.

In conclusion, tongue protrusion strength is greater in males compared to females, and decreases with age. If these differences also apply to patients with sleep apnoea, the reduction in maximal tongue protrusion force with age could be of relevance to the observed increase in prevalence and severity of sleep apnoea-hypopnoea syndrome in middle age, but would not explain the gender difference in prevalence.

Eur Respir J 1999; 14: 191-195.
\end{abstract}

The upper airway muscles, particularly the genioglossus and soft palatal muscles, have been extensively studied using electromyography. They are active during a wide range of activities including speech, deglutition and respiration [1-8]. The levels of muscle activity vary considerably with route and phase of respiration $[6,7]$ posture $[6,7]$ sleep state [8] sex [9] and hypoxia/hypercapnoea [10]. Studies demonstrating reflex activity in response to negative upper airway pressure stimuli $[6,7,11,12]$ suggest an important role in the maintenance of upper airway patency. Upper airway (UA) muscle fibre type has also been shown to vary between individuals as it does for other skeletal muscles [13], which suggests that strength and fatiguability may vary. Limb and respiratory muscle (diaphragm) strength and fatiguability have been extensively studied in man and are known to vary with hypoxia/ hypercapnoea [14-16], age [17] and sex [18]. However, force and fatiguability characteristics have not been studied in UA muscles.

It was hypothesized that UA muscles may demonstrate age and sex related force and fatiguability characteristics similar to other skeletal muscles. Therefore, the force and fatiguability characteristics of the functional unit that protrudes the tongue, namely the intrinsic tongue muscles and genioglossus, in a group of male and female subjects with a wide age range, were examined.
Respiratory Medicine Unit, Dept of Medicine, University of Edinburgh, Royal Infirmary, Edinburgh, EH3 9YW, Scotland, UK.

Correspondence: I.L. Mortimore

Cheltenham General Hospital

Sandford Road

Cheltenham

Gloucestershire GL53 7AN

UK

Fax: 441242274151

Keywords: Fat free mass

force

tongue protrusion

upper airway

Received: March 101998

Accepted after revision October 121998

This study was supported by the Wellcome Trust.

\begin{abstract}
Subjects
Eighty-six females and 81 males who reported that they did not snore and were not sleepy as assessed by the Epworth score [19], were studied after ethical committee approval and informed consent were obtained. Subjects were excluded if they had any disease or were taking any drugs, including hormones, which could influence neuromuscular function. Subjects were recruited from university and hospital staff, students and patients. Height $(\mathrm{Ht})$, weight $(\mathrm{wt})$, neck circumference [20] and skinfold thickness measurements were made in order to calculate fat free mass (FFM) [21, 22].
\end{abstract}

Materials and methods

\section{Force transducer}

The force transducer was made "in-house" using a 0-6 $\mathrm{kg}$ button load cell (Graham \& White Instruments Ltd, St Albans, UK). The transducer consisted of a machined nylon hand grip and mouthpiece (fig. 1). The mouthpiece consisted of a $1 \mathrm{~cm}$ diameter nylon plate behind which was positioned the load cell. Behind the plate the mouthpiece consisted of a groove approximately $2 \mathrm{~mm}$ deep and 


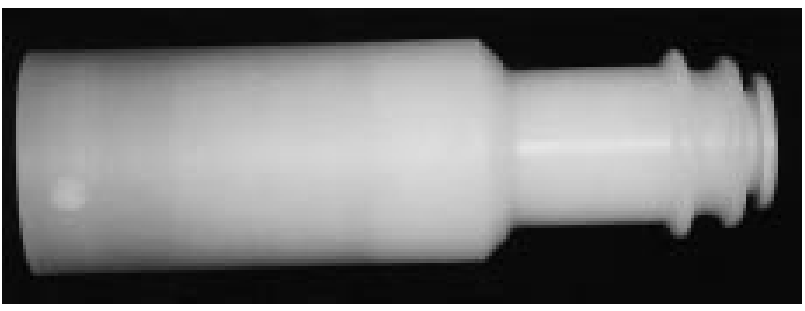

Fig. 1. - Force transducer. At the extreme right of the force transducer is the plate against which the tongue is pushed, and behind this is the groove in which the incisor teeth are placed in order to fix the position of the transducer.

$2 \mathrm{~mm}$ wide. Subjects were asked to rest their upper and lower incisor teeth in the groove in order to steady the transducer rather than to bite on the transducer, ensuring that when measuring fatiguability, tongue protrusion fatigue and not jaw grip fatigue was measured. The force transducer was therefore used with the mouth open just enough to accommodate the transducer (fig. 2). This opening was fixed in absolute terms $(\sim 1 \mathrm{~cm})$ but not in relative terms in relation to jaw anatomy. The end plate of the force transducer was deliberately placed just inside the teeth rather than in front, or a significant distance behind, so that the tongue would be working at a physiological length in each subject (at rest the tongue abuts the incisors). Force could then be exerted on the plate by the subjects tongue.

The movement of the plate on the button load cell during measurements was negligible $(<1 \mathrm{~mm})$. The transducer was connected to a linear visual scale displaying force in $\mathrm{N}$ or as a percentage of the subjects maximum force (measured during a previous trial), (fig. 3). The force transducer calibration was checked by fixing it vertically and placing weights of known mass on top of the force transducer $(1 \mathrm{~kg}=9.8 \mathrm{~N})$. The calibration range was linear between $0-60 \mathrm{~N}$.

\section{Protocol}

Subjects were seated upright and asked to look straight ahead during measurements of force and fatiguability. Maximum strength was measured by asking the subjects to push their tongues against the force transducer as hard as

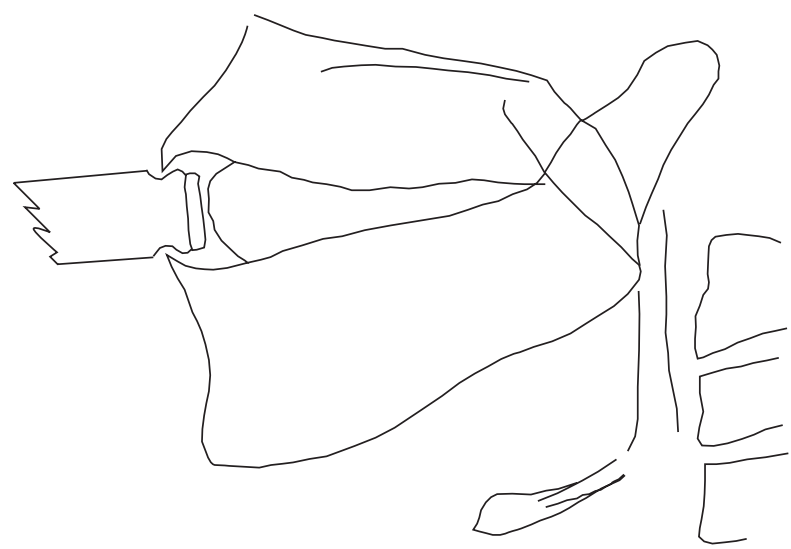

Fig. 2. - Diagrammatic representation based on a lateral cephalogram with the force transducer in position for measurement of maximum force and fatigue.

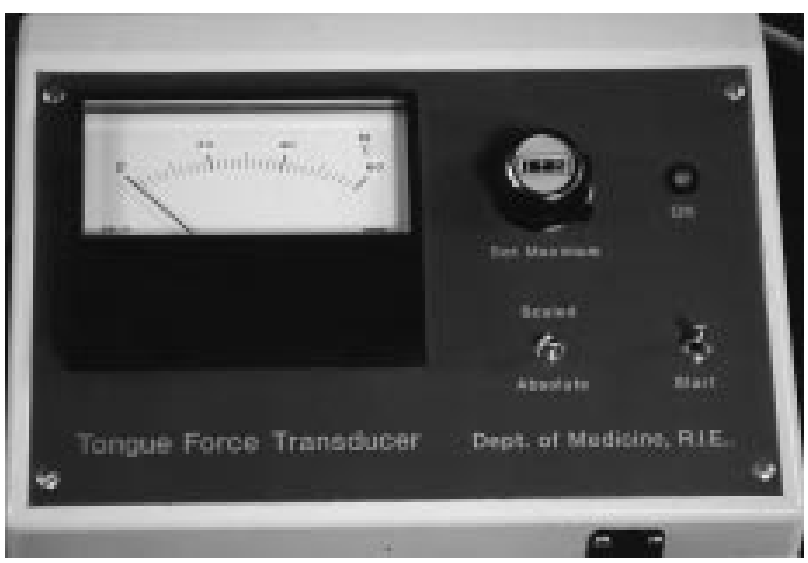

Fig. 3. - Control box with analogue scale capable of registering force in absolute units $(\mathrm{N})$ or as a percentage of maximum force.

possible (a procedure which is not uncomfortable). The maximum was taken as the greatest force produced in two trials, which in most cases were identical. If the two trials were not identical, further trials were performed until two identical maxima were produced. In practice, this did not require more than four trials in total. Subjects had to hold their maximum force for $2 \mathrm{~s}$ which is approximately the time taken to inspire when these muscles would normally be active. Subjects were then allowed to rest for $5 \mathrm{~min}$ whilst $\mathrm{Ht}$, Wt, neck circumference and skinfolds were measured. Fatiguability was then measured by asking the subjects to maintain $50 \%$ of their maximum force for as long as possible by watching the linear visual scale. They were told that when they could no longer maintain $50 \%$ they should relax their tongue, whereupon a rest period of $30 \mathrm{~s}$ began. After the $30 \mathrm{~s}$ rest subjects were asked to repeat the procedure twice more, giving three periods at $50 \%$ maximum tongue protrusion strength $(t 501, t 502, t 503)$. Fatiguability was compared using $t 501$ and also the total time (in s) subjects could maintain $50 \%$ of maximum force (i.e. the total of the three trials; $t 501+t 502+t 503=t$ tot $)$.

\section{Reproducibility}

Reproducibility of both $F_{\max }, t$ tot and $t 501$ were assessed in 10 subjects (age $35 \pm 14$ yrs) on five separate occasions on different days.

\section{Statistical analysis}

Variables were compared using t-tests and linear regression analysis as appropriate (SPSS for windows Chicago, IL, USA). Reproducibility was assessed as the coefficient of variation $((\mathrm{sD} /$ mean value $) \times 100)$. Comparison of linear regression slopes was carried out using confidence interval analysis [23].

\section{Results}

Mean age and anthropometric data $( \pm \mathrm{SD})$ are shown in table 1, together with the results of male/female comparisons. There was no difference in Epworth score between males and females. Males were significantly heavier and 
Table 1. - Comparison of anthropometric data in male and female subjects

\begin{tabular}{lccc}
\hline & $\begin{array}{c}\text { Males } \\
(\mathrm{n}=81)\end{array}$ & $\begin{array}{c}\text { Females } \\
(\mathrm{n}=86)\end{array}$ & p-value \\
\hline Height m & $1.78 \pm 0.1$ & $1.65 \pm 0.1$ & $<0.001$ \\
Weight kg & $77.0 \pm 10.9$ & $67.3 \pm 13.8$ & $<0.001$ \\
BMI kg·m & $24.8 \pm 4.6$ & $24.2 \pm 3.1$ & 0.3 \\
FFM kg & $66.1 \pm 8.5$ & $48.1 \pm 7.4$ & $<0.001$ \\
Body fat \% & $13.7 \pm 5.4$ & $27.7 \pm 5.9$ & $<0.001$ \\
Neck circumference cm & $38.4 \pm 2.8$ & $33.6 \pm 2.9$ & $<0.001$ \\
Age yrs & $43 \pm 19.0$ & $42.4 \pm 19.0$ & 0.8 \\
Epworth score & $5.3 \pm 3.1$ & $5.3 \pm 3.2$ & 0.9 \\
\hline
\end{tabular}

Data are presented as mean \pm SD. BMI: body mass index; FFM fat-free mass.

taller with greater fat-free mass (FFM), but there was no significant difference in body mass index (BMI).

Reproduciblity data is shown in table 2 for 10 subjects. Mean coefficients of variation for maximal tongue protrusion force $\left(F_{\max }\right), t$ tot and $t 501$ were $3 \%, 7 \%$ and $11 \%$ respectively.

$F \max$ was significantly and negatively correlated with age in both males $(r=-0.57 ; \mathrm{p}<0.001$, fig. $4 \mathrm{a})$ and females $(\mathrm{r}=-0.56 ; \mathrm{p}<0.001$, fig. $4 \mathrm{~b})$. The slope of the relationship was essentially the same for both males and females $(95 \%$ confidence intervals $-0.05-0.15)$. Correction of $F \max$ for FFM did not improve the correlation to age in either males $(r=0.5 ; p<0.001)$ or females $(r=0.55 ; p<0.001)$. Age was positively correlated with percentage body fat in both males $(\mathrm{r}=0.5 ; \mathrm{p}<0.001)$ and females $(\mathrm{r}=0.5 ; \mathrm{p}<0.001)$, and was neck circumference (males, $r=0.52 ; \mathrm{p}<0.001$ : females, $r=0.6 ; p<0.001)$. There was no correlation between age and FFM $(\mathrm{p}>0.05)$, or age and any of the indices of fatiguability $(\mathrm{p}>0.05)$ for either males or females. $F \max$ was significantly correlated with FFM in males $(\mathrm{r}=0.22$; $\mathrm{p}<0.001)$ but not in females $(\mathrm{r}=0.01 ; \mathrm{p}>0.5)$. None of the indexes of fatiguability were correlated to $F \max$ for males or females $(\mathrm{p}>0.05)$.

$F \max$ was significantly greater in males compared to females (table 3 ). However, if $F \max$ was corrected for FFM $(F \max / F F M)$ this sex difference was eradicated (table 3). There was no difference in any of the fatiguability indexes between males and females (table 3 ).

Table 2. - Reproducibility of maximal tongue protusion force $\left(F_{\text {max }}\right)$ and tot

\begin{tabular}{lccrrrr}
\hline $\begin{array}{l}\text { Subject } \\
\text { No. }\end{array}$ & $\begin{array}{c}\text { Mean } F \max \\
\mathrm{N}\end{array}$ & $\begin{array}{c}\text { CV } \\
\%\end{array}$ & $\begin{array}{c}\text { Mean } t \text { tot } \\
\mathrm{s}\end{array}$ & $\begin{array}{c}\text { CV } \\
\%\end{array}$ & $\begin{array}{r}\text { Mean } t 501 \\
\mathrm{~s}\end{array}$ & $\begin{array}{c}\text { CV } \\
\%\end{array}$ \\
\hline 1 & 30 & 4.6 & 94 & 11.0 & 29.2 & 9.5 \\
2 & 20 & 4.0 & 86 & 9.6 & 36.8 & 6.2 \\
3 & 30 & 1.7 & 97 & 4.0 & 44.2 & 6.8 \\
4 & 36 & 1.4 & 86 & 8.0 & 42.8 & 5.4 \\
5 & 23 & 2.4 & 67 & 6.2 & 31.6 & 14.6 \\
6 & 33 & 1.6 & 108 & 5.6 & 22.8 & 14.6 \\
7 & 38 & 2.0 & 110 & 8.0 & 35.4 & 11.4 \\
8 & 18 & 2.7 & 113 & 7.1 & 30.6 & 19.0 \\
9 & 33 & 7.0 & 98 & 5.9 & 33.8 & 15.0 \\
10 & 36 & 6.1 & 73 & 5.0 & 35.2 & 9.0 \\
\hline
\end{tabular}

CV: coefficient of variation; $t$ tot: total time at $50 \% F_{\max } t 501$ : time for initial trial at $50 \% F_{\max }$.
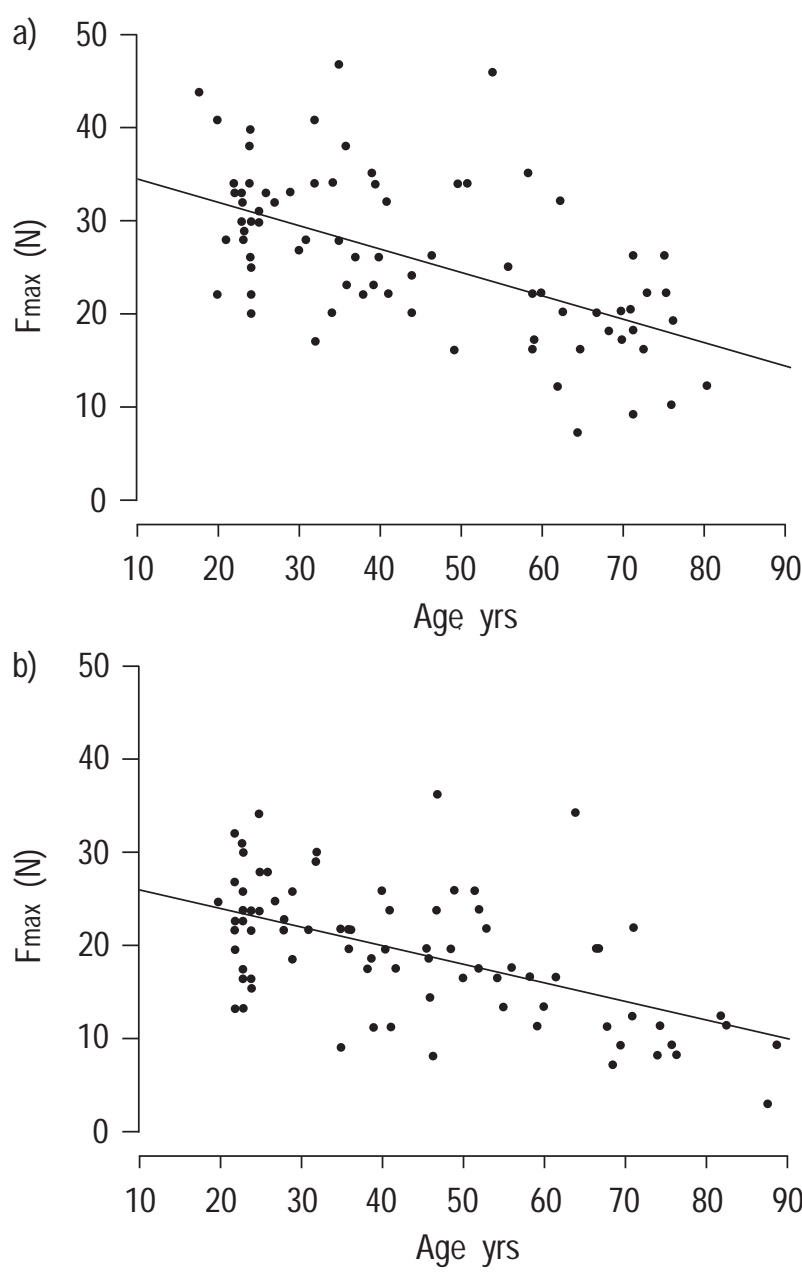

Fig. 4. - Relationship of maximum tongue protrusion force $\left(F_{\max }\right)$ to age in: a) 81 males; and b) 86 female subjects. Regression equations: a) $F_{\max }=-0.25$ age $\left.(\mathrm{yr})+37(\mathrm{r}=-0.57 ; \mathrm{p}<0.001) ; \mathrm{b}\right) F_{\max }=-0.2$ age $(\mathrm{yr})+$ $28(\mathrm{r}=-0.56 ; \mathrm{p}<0.001)$.

\section{Discussion}

This study has demonstrated that $F_{\max }$ decreases with age in both adult males and females and that there is no sex difference in tongue protrusion force once allowance is made for total body muscle mass using FFM. The percentage variance in tongue protrusion strength caused by age is, however, only around $30 \%$.

Table 3. - Tongue protrusion force and fatiguability in male and female subjects

\begin{tabular}{lccc}
\hline & $\begin{array}{c}\text { Males } \\
(\mathrm{n}=81)\end{array}$ & $\begin{array}{c}\text { Females } \\
(\mathrm{n}=86)\end{array}$ & p-value \\
\hline$F$ max N & $26.3 \pm 8.3$ & $19.9 \pm 6.7$ & $<0.001$ \\
$t$ tot S & $89.5 \pm 55.0$ & $85.3 \pm 40.5$ & 0.5 \\
$t 501 \mathrm{~s}$ & $32 \pm 14.0$ & $32 \pm 22.0$ & 0.9 \\
$t 502 \mathrm{~s}$ & $30 \pm 22.0$ & $26 \pm 11.0$ & 0.4 \\
$t 503 \mathrm{~S}$ & $28 \pm 16.0$ & $25 \pm 12.0$ & 0.3 \\
$F$ max/FFM N$\cdot \mathrm{kg}^{-1}$ & $0.4 \pm 0.1$ & $0.4 \pm 0.1$ & 0.3 \\
\hline
\end{tabular}

Data are presented as mean \pm SD. $F \max$ : maximum tongue protusion strength; $t$ tot: sum of three trials at $50 \%$ Fmax. $t 501$, t502, t503: time for first, second and third trials at 50\% Fmax. FFM: fat-free mass. 
Genioglossus reflex electromyographic activity in response to UA negative pressure increases retroglossal UA size in humans [24] by moving the tongue forwards. It has also been shown that genioglossus electromyographic activity is related to tongue protrusion force [25]. It could also be argued that tongue protrusion and maintenance of UA patency are dependent on the function of the intrinsic tongue muscles. If this is the case then the present study has still measured the force and fatiguability of the functional unit which protrudes the tongue and maintains UA patency.

The end plate of the force transducer was deliberately placed just inside the teeth rather than in front of or a significant distance behind, so that tongue protrusion would be occurring at a physiological length in each subject (at rest the tongue abuts the incisors). It has recently been suggested in studies on awake goats that genioglossal length and therefore, optimum performance, may be adversely affected by negative UA pressure [26]. Thus by altering the position of the force transducer relative to the teeth and optimizing muscle length in each subject, the value of $F$ max could have been increased but the measurement would not then have been truly physiological and any effects of the bony craniofacial structure in determining muscle length and therefore tongue protrusion performance would have been eliminated.

Fifty per cent of maximum force was chosen for the fatigue studies because this is a level of activity which commonly causes fatigue in $\sim 1 \mathrm{~min}$ for most skeletal muscles [27]. It has also been shown that for muscles contracting isometrically at least $15 \%$ of maximum force is necessary to induce fatigue, rising to $40 \%$ if contracting intermittently [28]. If lower percentages of maximum had been used the trial periods would have lengthened, which might have adversely affected subject motivation and cooperation and therefore decreased reproducibility. The rest periods were chosen as $30 \mathrm{~s}$ because full muscle recovery would be unlikely to occur within that time period (table 3 ) and this would allow further indices of fatiguability to be derived.

Reproducibility of $F$ max measurement was of the order of $3 \%$ which is acceptable for a physiological measurement. The reproducibility of fatigue measurements were around $7-11 \%$ which probably reflects the fact that this measurement is more likely to be effort/motivation dependent. However, many physiological measurements have similar reproducibility and therefore valid conclusions can be drawn.

In the present study both male and female subjects demonstrated significant and similar correlations between $F_{\max }$ and age (fig. 2) which is consistent with data for other skeletal muscles $[17,18]$. The decrease in tongue protrusion force with age could simply be related to loss of muscle mass. However, there was no significant relationship between FFM and age in either males or females. Thus, the reduction in tongue protrusion force in the present study seems to be a phenomenon unrelated to total body muscle mass per se. However, there were significant positive correlations between age and both percentage body fat and neck circumference, which suggests that as tongue protrusion force decreases mass loading of the UA may increase.

The male subjects were taller, heavier and had greater FFM's compared to female subjects, but age and BMI were identical for the two groups. $F_{\max }$ was greater in male subjects compared to female subjects matched for both age and BMI. However, after correction of $F \max$ for FFM $(F \max / \mathrm{FFM})$ there was no sex difference in tongue protrusion force $(\mathrm{p}=0.3$, table 3$)$, suggesting that males and females have equal tongue protrusion force on a force per unit of body muscle mass basis. However, it must be remembered that a measure of total body muscle mass (FFM) was used, not tongue mass.

In the present study, tongue protrusion fatiguability was not correlated to any other variable nor was there a significant sex or age effect difference. However, any possible effect of age on fatigubility could have been obscured because fatiguability was measured as a percentage of $F_{\max }$ (which decreases with age in the present study) rather than in absolute terms. This approach was necessary because the main aim of the study was to compare males with females.

These results were obtained in normal awake subjects. Their relevance to events during sleep is unknown. However, it is perhaps interesting to speculate on the relevance of the observation of a reduction in tongue protrusion strength with age to that of increasing severity and prevalence of sleep apnoea with age [29, 30]. Further investigation is required to determine whether the increased prevalence/severity of sleep apnoea hypopnoea syndrome with age $[29,30]$ could be related to decreasing tongue protrusion strength.

\section{References}

1. Kuehn DP, Folkins JW, Cutting CB. Relationships between muscle activity and velar position. Cleft Palate $J$ 1982; 19: 25-35.

2. Hrycyshyn AW, Basmajian JV. Electromyography of the oral stage of swallowing in man. Am J Anat 1972; 133: 333-340.

3. Launois SH, Tsui J, Woodrow-Weiss J. Respiratory function of the velopharyngeal constrictor muscles during wakefulness in normal adults. $J$ Appl Physiol 1997; 82: 584-591.

4. Mezzanotte WS, Tangel DJ, White DP. Waking genioglossal electromyogram in sleep apnoea patients versus normal controls (a neuromuscular compensatory mechanism). J Clin Invest 1992; 89: 1571-1579.

5. Mathur R, Mortimore IL, Douglas NJ. Effect of breathing, pressure and posture on palatoglosal and genioglossal tone. Clin Sci 1995; 89: 441-445.

6. Mortimore IL, Mathur R, Douglas NJ. Effect of posture, route of respiration and negative pressure on palatal muscle activity in humans. J Appl Physiol 1995; 79: 448454.

7. Mortimore IL, Douglas NJ. Palatopharyngeus has respiratory activity and responds to negative pressure in sleep apnoeics. Eur Respir J 1996; 9: 773-778.

8. Suratt PM, McTier RF, Wilhoit SC. Upper airway muscle activation is augmented in patients with obstructive sleep apnea compared with that in normal subjects. Am Rev Respir Dis 1988; 137: 889-894.

9. Popovic RM, White DP. Influence of gender on waking genioglossal electromyogram and upper airway resistance. Am J Respir Crit Care Med 1995; 152: 725-731.

10. Van der Touw T, O'Neill N, Amis T, Wheatley J, Brancatisano A. Soft palate muscle activity in response to hypoxic hypercapnia. J Appl Physiol 1994; 77: 2600-2605. 
11. Horner RL, Innes JA, Guz A. Evidence for reflex upper airway dilator muscle activation by sudden negative airway pressures in man. J Physiol (Lond) 1991; 436: 1529.

12. Mortimore IL, Douglas NJ. Palatal muscle EMG response to negative pressure in awake sleep apneic and control subjects. Am J Respir Crit Care Med 1977; 156: 867-873.

13. Series F, Cote C, Simoneau J-A, et al. Physiologic, metabolic, and muscle fiber type characteristics of musculus uvulae in sleep apnea hypopnea syndrome and in snorers. J Clin Invest 1995; 95: 20-25.

14. Esau SA. Hypoxic, hypercapneic acidosis decreases tension and increases fatigue in hamster diaphragm muscle in vitro. Am Rev Respir Dis 1989; 139: 1410-1417.

15. Jardim J, Farkas G, Prefaut C, Thomas D, Macklem PT, Roussos C. The failing respiratory muscles under normoxic and hypoxic conditions. Am Rev Respir Dis 1981; 124: 274-279.

16. Juan G, Calverley P, Talamo C, Schnader J, Roussos C. Effect of carbon dioxide on diaphragmatic function in human beings. N Engl J Med 1984; 310: 874-879.

17. Grimby G, Saltin B. Mini Review: The ageing muscle. Clin Physiol 1983; 3: 209-218.

18. Astrand P-O, Rodahl K. Textbook of work physiology. 2nd Edn. New York, McGraw-Hill, 1977.

19. Johns MW. A new method for measuring daytime sleepiness: the Epworth sleepiness scale. Sleep 1991; 14: 540545.

20. Stradling JR, Crosby JH. Predictors and prevalence of obstructive sleep apnoea and snoring in 1001 middle aged men. Thorax 1992; 46: 85-90.
21. Durnin JVGA, Rahaman MM. The assessment of the amount of fat in the human body from measurements of skinfold thickness. Br J Nutr 1967; 21: 681-689.

22. Durnin JVGA, Womersley J. Body fat and skinfolds. Br J Nutr 1974; 32: 77-97.

23. Gardner MJ, Altman MJ. Statistics with confidence. London, BMJ 1994.

24. Kobayashi I, Perry A, Rhymer J, et al. Relationship between the electrical activity of tongue protrusion muscle activity and the upper airway patency: a study in laryngectomised subjects. Am J Respir Crit Care Med 1994; 149: A148.

25. Mortimore IL, Douglas NJ. Relationship of tongue protrusion muscle electromyographic activity to force. $\mathrm{Am} \mathrm{J}$ Respir Crit Care Med 1996; 153: A690.

26. Brennick MJ, Parisi RA, England SJ. Influence of preload and afterload on tongue protrusion muscle length in awake goats. Am J Respir Crit Care Med 1997; 155: 2010-2017.

27. Rohmert W. Die beziehung zwischen kraft und ausdauer bei statischer muskelarbeit. Schriftenreihe Arbeitsmedizin, Sozialmedizin, Arbeitshygiene. Stuttgart, Gentner Verlag, 1968; p. 118

28. Macklem PT, Roussos C. Respiratory muscle fatigue: a cause of respiratory failure. Clin Sci 1997; 53: 419-422.

29. Jennum P, Sjol A. Epidemiology of snoring and obstructive sleep apnoea in a Danish population age 30-60. J Sleep Res 1992; 1: 240-244.

30. Young T, Palta M, Dempsey J, Skatrud J, Webber S, Bader S. The occurrence of sleep-disordered breathing among middle-aged adults. $N$ Engl $J$ Med 1993; 328: $1230-1235$. 